\title{
Powder Diffraction: Theory and Practice-a new and comprehensive book on the methods and applications of powder diffraction
}

In early 2008, a new book entitled Powder Diffraction: Theory and Practice, published by the Royal Society of Chemistry (Cambridge), was released. It caught my attention and curiosity not just because its main title shares the same with this journal, but also because one of the editors is Dr. Robert E. Dinnebier. I have known Robert for over 15 years, and the first time I met Robert was when I visited Professor Walter Eysel's X-ray laboratory at the University of Heidelberg in 1993. Robert was a Ph.D. student of Professor Eysel at that time. Robert and I had a chance to discuss our work together, and I came away with a deep impression that he is a very careful, intelligent, organized, and talented scientist. Robert is now one of the most renowned experts in the field of powder diffraction and materials science.

I think the editors stated it best in the preface that "this book is an advanced introductory text about modern methods and applications of powder diffraction in research" and that "this book presents a broad overview of current methods and applications, including their theory and practice, with useful information on getting started in these methods. The book is written by renowned experts in the respective techniques." This is indeed a very impressive 582-page book with 19 chapters. These 19 chapters can be grouped into five main parts.

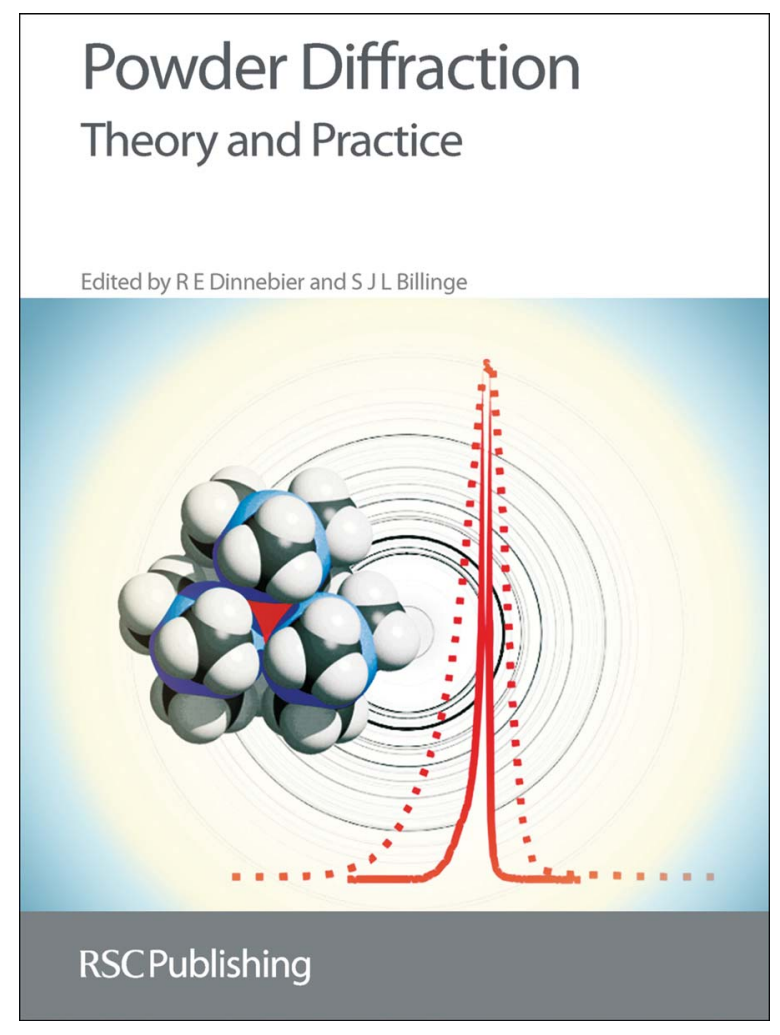

Part 1 includes the first three chapters describing principles, experimental, and intensities for powder diffraction. This part is powder diffraction 101, which is very useful to students and scientists who want to start using powder diffraction techniques.

Part 2 contains a group of four chapters on the subject of the reduction of experimental diffraction data. This part contains a large amount of important and useful information for a scientist who wants to do basic data reduction of experimental data. In the reduction of experimental data, peak research is usually the first and most important step to locate diffraction peaks and to determine their positions and intensities. Many diffraction analysis packages include basic data reduction programs. During my editing of manuscripts submitted for publication in Powder Diffraction, I have noticed that many authors do not understand how diffraction peaks were identified and determined by the programs used during diffraction analysis. This part of the book explains peak search and automatic indexing information that should be understood by every scientist performing diffraction analysis.

Part 3 with three chapters describes techniques used for crystal-structure determination from powder data. Crystalstructure determination is one of the most, if not the most, popular fields in powder diffraction analysis. The editors did an excellent job in systematically presenting fundamentals and advanced $a b$ initio crystal-structure determination techniques. Part 3 begins with a description of the direct methods and the direct-space techniques used to obtain crystalstructure solution from powder data. The popular Rietveld refinement method with constraints and restraints are also described. The recently proposed derivative difference minimization method of full-profile refinement is also given. The advantage of this method is the possibility of profile refinement without background line modeling.

Part 4 is on other powder diffraction analytical techniques for materials characterization. There are six chapters with almost 200 pages of text on commonly used and special applications of powder diffraction techniques including quantitative phase analysis, micro-structural determinations of texture and strain/stress, domain size, lattice defect, twodimension diffraction using area detectors, non-ambient diffraction, and local structure from pair distribution function. This part of the book is most useful to material scientists.

Part 5 (or Chapter 17) is the longest chapter with 35 tables on available computer software for all types of powder diffraction analysis. Computer programs for the same application are listed in the same table so that it is clear which programs are available for a particular type of diffraction 
analysis. For example, there are a total of 30 computer programs in the table for Rietveld structure refinement and 31 for visualization and photo realistic rendering of crystal structures. The amount of effort and time required to prepare these tables must had been tremendous. This chapter is a unique, key reference for any scientist interested in using computer software for powder diffraction analysis.

However, there is one drawback to the book. No titles of journal articles are included in the references section at the end of the majority of the 17 chapters. Article titles help readers understand the content of references before deciding whether or not to retrieve the references.
One of my colleagues said to me that this book is so thick that it looks and feels like a dictionary. This book may not be a real dictionary, but it certainly contains an enormous amount of useful information on major topics and techniques for powder diffraction. This comprehensive book has become one of my favorite references on powder diffraction-I use this book to help me edit manuscripts for Powder Diffraction. I believe that every powder diffraction scientist should have a copy of this book.

Ting C. Huang Editor-in-Chief 